\title{
Iris Melanoma pT1 TNM Finding v8
}

National Cancer Institute

\section{Source}

National Cancer Institute. Iris Melanoma pT1 TNM Finding v8. NCI Thesaurus. Code C140618.

Iris melanoma with tumor limited to the iris. (from AJCC 8th Ed.) 